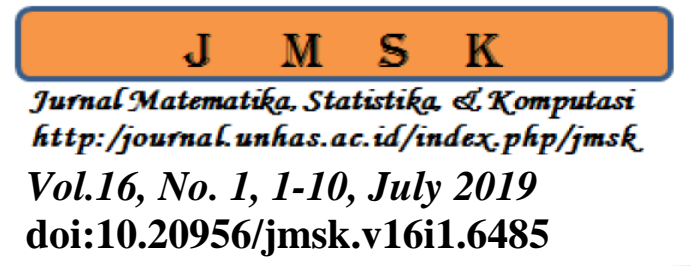

e-ISSN: 2614-8811

\title{
MONITORING VARIABILITAS PROSES BERDASARKAN STATISTIK WILKS
}

\author{
Suci Barlian Sari ${ }^{1^{*}}$, Erna Tri Herdiani ${ }^{2 *}$, Nasrah Sirajang ${ }^{3 *}$
}

\begin{abstract}
In a manufacturing industry quality problems often occur. One of the main cause is due to variability process. Variability process is a variation that occurs in the process, both in manufacturing and non-manufacturing processes. One method for monitoring variabiliti process is by using Wilks Statistics. Wilks statistics is a method that is used based on individual observations. This study aims to monitor the variability of the process and apply it to Electric Resistance Welded (ERW) pipes with the Wilks statistical method. In addition, a capability process analysis is also carried out when the Wilks control chart has been controlled. The result showed that all observations carried out individually were in control limit with a capability process of 2.5386, which means the process capability of ERW pipe production using a multivariate Wilks statistical control chart was capable and match with the specifications limit specified by company.
\end{abstract}

Keywords: Control Chart, Wilks Statistics, Variability Process

\begin{abstract}
Abstrak
Dalam suatu industri manufaktur seringkali terjadi masalah kualitas. Salah satu penyebab utamanya adalah karena adanya variabilitas proses. Variabilitas proses merupakan variasi yang terjadi didalam proses, baik dalam proses manufaktur maupun non manufaktur. Salah satu metode untuk memonitor variabilitas proses adalah dengan menggunakan Statistik Wilks. Statistik Wilks merupakan salah satu metode yang penggunaanya berdasarkan observasi secara individu. Penelitian ini bertujuan untuk memonitor variabilitas proses serta menerapkannya pada pipa Electric Resistance Welded (ERW) dengan metode statistik Wilks. Selain itu, dilakukan analisis kapabilitas prosesnya ketika bagan kendali Wilks telah terkendali. Hasil penelitian menunjukkan bahwa semua pengamatan yang dilakukan secara individu berada dalam batas kendali dengan kemampuan proses sebesar 2,5386 artinya kapabilitas proses dari produksi pipa ERW menggunakan bagan kendali statistik Wilks secara multivariat telah capable dan sangat baik serta sesuai dengan batas spesifikasi yang telah di tentukan oleh perusahaan.
\end{abstract}

Kata Kunci : Bagan Kendali, Statistik Wilks, Variabilitas Proses.

\section{Pendahuluan}

*Program Studi Statistika, Universitas Hasanuddin

Email address: ${ }^{1}$ suciberliansari@gmail.com, ${ }^{2}$ herdiani.erna@gmail.com, ${ }^{3}$ nas.sirajang@gmail.com 


\section{Suci Barlian Sari, Erna Tri Herdiani, Nasrah Sirajang}

Persaingan dunia industri saat ini semakin hari semakin ketat, menyebabkan banyak perusahaanperusahaan berlomba untuk menciptakan produk yang lebih baik. Hal ini dikarenakan tersedianya sumber daya yang dimiliki perusahaan baik sumber daya manusia maupun sumber daya yang lain ditambah pula perkembangan teknologi yang semakin hari semakin canggih. Salah satu penyebab utama munculnya masalah kualitas dalam suatu industri adalah karena adanya variabilitas proses. Variabilitas proses merupakan variasi yang terjadi didalam proses baik proses manufaktur maupun non manufaktur. Variasivariasi ini dapat terjadi dikarenakan adanya variasi dalam elemen-elemen proses, yaitu manusia, mesin, metode, material dan lingkungan sehingga diperlukan pengendalian variabilitas proses. Pengendalian variabilitas proses merupakan salah satu dasar yang digunakan dalam industri untuk meningkatkan kualitas proses produksi. Pengendalian variabilitas proses menjadi faktor penting dalam meningkatkan kemampuan bersaing suatu produk dan memperbesar target pasar. Salah satu teknik yang digunakan untuk mengendalikan variabilitas proses adalah dengan menggunakan bagan kendali.

Beberapa penelitian sebelumnya yang berkaitan dengan pengendalian variabilitas proses diantaranya, Sahabuddin dkk [7] melakukan penelitian dengan menggunakan vektor variansi dalam mengendalian variabilitas proses. Kemudian, Djauhari [2] memperkenalkan penelitian dengan memantau variabilitas proses berdasarkan pengamatan individu. Susanto [8] melakukan pengendalian kualitas dengan $T^{2}$ Hotelling dan peta kendali Generalized Variance. Meason dkk [4] memperkenalkan metode baru dalam memantau variabilitas yang kemudian dikembangkan oleh Noor dan Djauhari [6] pada proses pembuatan Beltline Moulding yaitu dengan menggunakan Statistik Wilks. Statistik Wilks merupakan salah satu metode yang penggunaannya dilakukan berdasarkan observasi secara individual. Kelebihan dari metode ini adalah kinerjanya sangat baik dalam mengatasi out of control [2]. Pada penelitian ini penulis menggunakan data multivariat yang terdiri dari 3 variabel dan mengaplikasikan metode Statistik Wilks pada pada data pipa Electric Resistance Welded (ERW) di PT.X.

\section{Tinjauan Pustaka}

\subsection{Matriks Data Multivariat}

[3] Pengamatan multivariat tunggal adalah kumpulan pengukuran pada $p$ variabel berbeda yang diambil pada objek atau percobaan yang sama. Jika $n$ pengamatan telah diperoleh, seluruh kumpulan data dapat ditempatkan pada matriks berukuran $n \times p$.

$$
\boldsymbol{X}_{\boldsymbol{n} \times \boldsymbol{p}}=\left[\begin{array}{cccccc}
x_{11} & x_{12} & \cdots & x_{1 j} & \cdots & x_{1 p} \\
x_{21} & x_{22} & \cdots & x_{2 j} & \cdots & x_{2 p} \\
\vdots & \vdots & \cdots & \vdots & \cdots & \vdots \\
x_{i 1} & x_{i 2} & \cdots & x_{i j} & \cdots & x_{i p} \\
\vdots & \vdots & \cdots & \vdots & \cdots & \vdots \\
x_{n 1} & x_{n 2} & \cdots & x_{n j} & \cdots & x_{n p}
\end{array}\right]=\left[\begin{array}{c}
\boldsymbol{x}_{\mathbf{1}}{ }^{\prime} \\
\boldsymbol{x}_{\mathbf{2}}{ }^{\prime} \\
\vdots \\
\boldsymbol{x}_{\boldsymbol{n}}{ }^{\prime}
\end{array}\right] \quad \leftarrow \text { observasi pertama }
$$

dengan $x_{i j}=$ pengamatan ke- $i$ variabel ke- $j ; n=$ jumlah observasi; $p=$ jumah variabel.

\subsection{Uji Normalitas Multivariat}

[3] Pengujian asumsi normal multivariat dapat dilakukan dengan menghitung ukuran jarak mahalanobis pada setiap pengamatan dan nilai Chi-Square. Hipotesis yang akan digunakan adalah sebagai berikut.

$H_{0}$ : Data berdistribusi normal multivariat 


\section{Suci Barlian Sari, Erna Tri Herdiani, Nasrah Sirajang}

$H_{1}$ : Data tidak berdistribusi normal multivariat

Uji normalitas ini dilakukan dengan membuat plot jarak Mahalanobis $\left(d_{i}^{2}\right)$ dan distribusi Chi-Square $\left(\chi_{\frac{1}{n}(i-0,5), p}^{2}\right)$. Langkah-langkahnya sebagai berikut:

1. Menghitung jarak Mahalanobis dengan rumus $d_{i}^{2}=\left(\boldsymbol{X}_{i}-\mu\right)^{\prime} \boldsymbol{\Sigma}^{-1}\left(\boldsymbol{X}_{i}-\mu\right)$

2. Setiap $d_{i}^{2}$ akan mengikuti sebaran Chi-Square $\chi_{\frac{1}{n}(i-0,5), p}^{2}$ dengan $\chi_{\frac{1}{n}(i-0,5), p}^{2}$ adalah distribusi ChiSquare dengan $p$ adalah banyaknya variabel prediktor.

3. Mengurutkan nilai $d_{i}^{2}$ dari nilai $d_{i}^{2}$ terkecil sampai $d_{i}^{2}$ terbesar. Plot Chi-Square akan memeriksa apakah $d_{i}^{2}$ mengikuti sebaran Chi-Square atau tidak dengan mengurutkan nilai $d_{i}^{2}$.

4. Membuat plot antara $\left(d_{i}^{2} ; \chi_{\frac{1}{n}(i-0,5), p}^{2}\right)$.

5. $H_{0}$ diterima jika lebih dari $50 \%$ nilai $d_{i}^{2} \leq \chi_{\frac{1}{n}(i-0,5), p}^{2}$, ini berarti data berdistribusi normal multivariat. Jika lebih kecil dari 50\% maka $H_{0}$ ditolak.

\subsection{Uji Independensi}

Uji Independensi atau disebut juga dengan uji Barlett merupakan pengujian yang digunakan untuk mengetahui hubungan antara variabel yang akan diteliti. Variabel $X_{1}, X_{2}, \ldots . . X_{p}$, dikatakan bersifat saling bebas jika matriks korelasi antar variabel membentuk matriks identitas [6]. Untuk menguji kebebasan antar variabel tersebut dilakukan uji Bartlett dengan hipotesis sebagai berikut:

$\mathrm{H}_{0}: R=\mathrm{I}$ (antar variabel tidak berkorelasi)

$\mathrm{H}_{1}: R \neq \mathrm{I}$ (antar variabel berkorelasi)

Statistik Uji:

$$
\chi_{\text {hitung }}^{2}=\left[n-2-\frac{2 p+5}{6}\right] \ln |R|
$$

\subsection{Peta Kendali Generalized Variance}

Peta kendali generalizel variance $(|\mathrm{S}|)$ merupakan salah satu alat untuk pengendali variabilitas proses dimana data pengamatan bersifat multivariat [5]. Variabilitas proses dinyatakan sebagai matrik kovarian $\sum$ berukuran $p \times p$. Diagonal utama dari matrik ini adalah variasi dari variabel proses secara individual dan data selain diagonal utama adalah kovarians. Matriks kovarian $\sum$ biasa ditaksir oleh matrik kovarian sampel $\mathbf{S}$ berdasarkan analisis sampel pendahuluan.

Adapun batas control untuk diagram control $|\mathrm{S}|$ adalah sebagai berikut:

$$
\begin{aligned}
& \mathrm{UCL}=\frac{|S|}{b_{1}}\left(b_{1}+\sqrt{3 b_{2}}\right) \\
& \mathrm{CL}=|\mathrm{S}| \\
& \mathrm{LCL}=\frac{|S|}{b_{1}}\left(b_{1}-\sqrt{3 b_{2}}\right)
\end{aligned}
$$

\subsection{Statistik Wilks}

Statistik Wilks merupakan metode yang diperkenalkan oleh Mason, Chou and Young [4] untuk mengidentifikasi out of control dari proses kualitas statistik. Statistik Wilks ini sangat penting dalam aplikasi industri karena memiliki interpretasi geometris dan sederhana serta mudah diaplikasikan ketika $\mathrm{p}$ tidak terlalu besar [2]. 


\section{Suci Barlian Sari, Erna Tri Herdiani, Nasrah Sirajang}

Proses kerja dari statistik Wilks juga membagi data pengamatan menjadi 2 yaitu fase I yang disebut juga sebagai Historical Data Set (HDS) dan fase II yang disebut juga Augmented Data Set (ADS). Untuk memonitor variabilitas proses dengan metode Statistik Wilks digunakan rumus:

$$
W=\frac{\left|S S_{H D S}\right|}{\left|S S_{A D S}\right|}=\left(\frac{n-1}{n}\right)^{p} \frac{\left|S_{H D S}\right|}{\left|S_{A D S}\right|}
$$

Dengan:

$W=$ Nilai Wilks dimana $0<\mathrm{W}<1$

$n=$ banyaknya data pada observasi individu

$p=$ banyaknya variabel

$\left|S_{H D S}\right|=$ Generalized Variance dari HDS

$\left|S_{A D S}\right|=$ Generalized Variance dari ADS

\subsection{Indeks Kemampuan Proses}

Analisis Kapabilitas proses adalah suatu analisis yang digunakan untuk menaksir kemampuan proses. Analisis kapabilitas proses dapat digunakan setelah proses produksi telah terkendali secara statistik. Berikut merupakan kriteria nilai kapabilitas [1].

1. $C p=1$, Kemampuan proses sesuai

2. $C p>1$, Kemampuan proses sangat baik (tingkat presisi dan akurasi tinggi)

3. $C p<1$, Kemampuan proses tidak baik

\section{Metodologi Penelitian}

Data yang digunakan pada tugas akhir ini adalah data sekunder dari Divisi Quality Control PT. X yang diperoleh dari skripsi Susanto [8]. Data tersebut merupakan data pengujian produk pipaERW dengan karakteristik kualitas diameter, panjang (length), dan berat (weight). Data dibagi dalam 2 tahap yaitu tahap pertama sebagai data pendahuluan yang diambil pada periode Januari-Juni dan tahap kedua sebagai data monitoring diambil pada periode bulan Juli-Desember. Variabel penelitian yang digunakan untuk penelitian ini adalah adalah diameter, panjang (length), dan berat (weight).

Langkah-langkah penelitian yang akan dilakukan dalam tugas akhir adalah sebagai berikut.

1. Melakukan kajian teoritis dalam memonitor variabilitas proses berdasarkan persamaan (2.4).

2. Melakukan uji normalitas pada data tahap I.

3. Melakukan uji independensi menggunakan uji Bartlett.

4. Menghitung matriks varian kovarian dari data tahap I.

5. Menghitung determinan dari $\left|S_{H D S}\right|$.

6. Melakukan kembali pengujian normalitas dan uji independensi pada data tahap II.

7. Menghitung matriks varian kovarian serta determinan pada data tahap II sebanyak $k$ pengamatan.

8. Menghitung nilai wilks sebanyak $k$.

9. Memplot nilai Wilks dan LCL untuk melihat variabilitas proses pada pipa ERW.

10. Menentukan indeks kapabilitas proses (cpm) setelah semua proses terkendali.

11. Menarik kesimpulan. 


\section{Suci Barlian Sari, Erna Tri Herdiani, Nasrah Sirajang}

\section{Hasil dan Pembahasan}

\subsection{Monitoring Variabilitas Proses Berdasarkan Statistik Wilks}

Misalkan terdapat matriks data $X$ berkuran $(n x p)$ menunjukkan observasi acak $n$ yang berdimensi $p$ dari sebuah proses yang sudah terkendali pada tahap I. Asumsikan matriks data sebagai HDS dan asumsikan bahwa pengamatan tersebut mengikuti distribusi normal multivariat dengan vektor rata-rata $\boldsymbol{\mu}_{\mathbf{0}}$ dan matriks kovarian $\sum_{\mathbf{0}}, \boldsymbol{N}_{\boldsymbol{p}}\left(\boldsymbol{\mu}_{\mathbf{0}}, \sum_{\mathbf{0}}\right)$. Secara sederhana dapat dituliskan dalam matriks $X$ pada Persamaan (4.1) dengan notasi sebagai berikut:

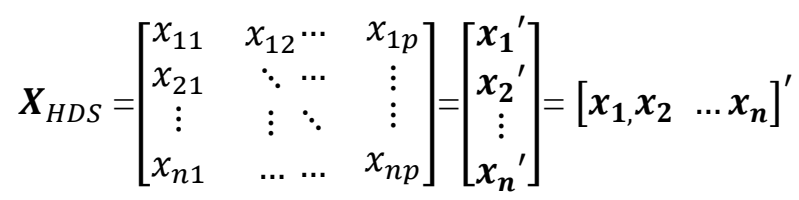

Dengan, $x_{\mathbf{1}}^{\prime}=\left[\begin{array}{lll}x_{i 1}, x_{i 2} & \ldots & x_{i n}\end{array}\right]$.

Pada tahap I yaitu HDS parameter $\boldsymbol{\mu}_{0}$ dan $\sum_{0}$ tidak diketahui, oleh karena itu $\boldsymbol{\mu}_{0}$ dan $\sum_{0}$ masing-masing ditaksir menggunakan $\mathbf{S}$ dan $\overline{\boldsymbol{x}}$ dari sampel. Berikut merupakan persamaan dari $\mathbf{S}$ dan $\overline{\boldsymbol{x}}$ yang dapat dituliskan pada Persamaan (4.2):

$$
\boldsymbol{S}_{H D S}=\frac{1}{i=1} \sum_{n-1}^{n}\left(\boldsymbol{x}_{\boldsymbol{i}}-\overline{\boldsymbol{x}}_{H D S}\right)\left(\boldsymbol{x}_{\boldsymbol{i}}-\overline{\boldsymbol{x}}_{H D S}\right)^{\prime}
$$

Dengan $\overline{\boldsymbol{x}}_{H D S}=\left[\begin{array}{c}\overline{\boldsymbol{x}}_{\mathbf{1}} \\ \overline{\boldsymbol{x}}_{\mathbf{2}} \\ \vdots \\ \overline{\boldsymbol{x}}_{\boldsymbol{p}}\end{array}\right]$ adalah vektor rata-rata sampel dari HDS.

Dimana, $\bar{x}_{i}=\frac{1}{n} \sum_{r=1}^{n} x_{r i}$ adalah sebagai variabel.

Jika semua variabel sudah terkendali, maka akan dilanjutkan pada tahap II untuk memeriksa apakah parameter yang diestimasi pada tahap I sudah tepat dengan cara memantau variabilitas prosesnya menggunakan pengamatan baru yang dilakukan secara individu.

Misalkan diberikan matriks data dari tahap II sebagai berikut:

$X_{A D S}=\left[\boldsymbol{x}_{1}^{\prime}, \boldsymbol{x}_{2}^{\prime}, \ldots \boldsymbol{x}_{n+1}{ }^{\prime}\right]^{\prime}$ maka matriks kovariansi sampel dari ADS adalah:

$$
\boldsymbol{S}_{A D S}=\frac{1}{n} \sum_{i=1}^{n+1}\left(x_{i}-\bar{x}_{A D S}\right)\left(x_{i}-\bar{x}_{A D S}\right)^{\prime}
$$

dimana $\overline{\boldsymbol{x}}_{A D S}=\left[\begin{array}{c}\bar{x}_{1} \\ \bar{x}_{2} \\ \vdots \\ \bar{x}_{p}\end{array}\right]$ adalah vektor rata-rata sampel dari ADS dengan:

$$
\bar{x}_{i}=\frac{1}{n+1} \sum_{r=1}^{n+1} x_{r i}
$$




\section{Suci Barlian Sari, Erna Tri Herdiani, Nasrah Sirajang}

Oleh karena itu, berdasarkan persamaan (2.4) untuk memonitor variabilitas proses pada tahap II dapat didefinisikan pada Persamaan (4.4) berikut:

$$
W=\frac{\left|S S_{H D S}\right|}{\left|S S_{A D S}\right|}=\left(\frac{n-1}{n}\right)^{p} \frac{\left|S_{H D S}\right|}{\left|S_{A D S}\right|}
$$

dengan:

$W=$ Nilai Wilks

$n=$ banyaknya data pada observasi individu

$p=$ banyaknya variabel

$\left|S_{H D S}\right|=$ Generalized Variance dari HDS

$\left|S_{A D S}\right|=$ Generalized Variance dari ADS

\subsection{Batas Kendali Statistik Wilks}

Untuk menentukan batas kendali dari Wilks maka digunakan hubungan antara distribusi $\mathrm{W}$ dan $T^{2}$ Hotelling. hubungan distribusi $\mathrm{W}$ dan $T^{2}$ Hotelling dapat dituliskan sebagai berikut:

$$
W=1-\frac{(n+1)}{n^{2}} T^{2}
$$

Dengan,

$$
T^{2}=\left(\boldsymbol{x}_{n+1}-\overline{\boldsymbol{x}}_{A D S}\right)^{\prime} \boldsymbol{S}^{-\mathbf{1}}{ }_{A D S}\left(\boldsymbol{x}_{n+1}-\overline{\boldsymbol{x}}_{A D S}\right)
$$

Berdasarkan distribusi $\mathrm{W}$, maka LCL dari Wilks adalah

$$
L C L=\operatorname{Beta}_{\left(\alpha, \frac{p}{2}, \frac{n-p}{2}\right)}
$$

\subsection{Karakteristik Kualitas Pipa ERW Tahap I}

Analisis karakteristik secara umum dapat dilakukan dengan ringkasan statistik deskriptif untuk mencari rata-rata, standar deviasi, varians, nilai minimum dan nilai maksimum dari data proses produksi pipa ERW pada tahap I seperti ditunjukkan pada Tabel 4.1 berikut:

Tabel 4.1 Statistika Deskriptif Karakteristik Kualitas Pipa ERW Tahap I

\begin{tabular}{llllll}
\hline Variabel & Mean & Varians & Nilai Min & $\begin{array}{l}\text { Nilai } \\
\text { Maks }\end{array}$ & Batas Spesifikasi \\
\hline Diameter $(\mathrm{mm})$ & 88,26 & 0,0139 & 88,05 & 88,45 & $88 \pm 0,5 \mathrm{~mm}$ \\
\hline Panjang (meter) & 6,0321 & 0,00001 & 6,0267 & 6,0417 & $6 \pm 0,05 \mathrm{~m}$ \\
\hline Berat $(\mathrm{kg})$ & 45,631 & 0,0536 & 45,235 & 45,882 & $45 \pm 1 \mathrm{~kg}$ \\
\hline
\end{tabular}

Sumber: Data diolah, 2019

Berdasarkan Tabel 4.1 diatas, dapat dideskripsikan bahwa karakteristik kualitas pipa ERW tahap I dengan rata-rata diameter pipa sebesar $88,26 \mathrm{~mm}$ dengan nilai target sebesar $88 \mathrm{~mm}$, nilai varians sebesar 0,0139 dengan minimum sebesar $88,05 \mathrm{~mm}$ dan nilai maksimum sebesar $88,45 \mathrm{~mm}$. Rata-rata panjang pipa ERW adalah sebesar 6,0321 meter dengan nilai target sebesar 6 meter, nilai varians cukup kecil yaitu sebesar 0,00001 meter. Berat pipa ERW rata-rata sebesar 45,631 kg dengan nilai target sebesar $45 \mathrm{~kg}$. 


\section{Suci Barlian Sari, Erna Tri Herdiani, Nasrah Sirajang}

Berdasarkan statistik deskriptif tersebut, maka nilai rata-rata semua variable berada dalam spesifikasi yang ditetapkan.

\subsection{Pengendalian Variabilitas Proses pada Tahap I}

Pengendalian variabilitas proses produksi pipa ERW menggunakan peta kendali Generalized variance.berdasarkan hasil yang diperoleh pada peta kendali tersebut menunjukkan bahwa batas atas (UCL) sama dengan 5,613 dan garis tengahnya nilai determinan matriks varian kovarians $|\mathrm{S}|$ menjadi 2,186 . Secara visual semua data berada dalam batas kendali dan tidak terdapat data yang out of control sehingga tahap I dikatakan berada dalam keadaan terkendali. Sampel yang diambil dari proses yang sudah berada dalam keadaan terkendali, disebut himpunan sampel historis atau disebut juga sebagai Historical Data Set (HDS).

\subsection{Karakteristik Kualitas Pipa ERW Tahap II}

Sama halnya pada karakteristik kualitas pipa ERW Tahap I, secara umum dapat dilakukan dengan ringkasan statistik deskriptif untuk mencari rata-rata, standar deviasi, varians, nilai minimum dan nilai maksimum dari data proses produksi pipa ERW pada tahap II seperti ditunjukkan pada Tabel 4.2 berikut:

Tabel 4.2 Statistika Deskriptif Proses Produksi Pipa ERW Tahap II

\begin{tabular}{llllll}
\hline \multicolumn{1}{c}{ Variabel } & Mean & Varians & $\begin{array}{c}\text { Nilai } \\
\text { Min }\end{array}$ & $\begin{array}{c}\text { Nilai } \\
\text { Maks }\end{array}$ & $\begin{array}{c}\text { Batas } \\
\text { Spesifikasi }\end{array}$ \\
\hline Diameter $(\mathbf{m m})$ & 88,185 & 0,0128 & 87,975 & 88,460 & $88 \pm 0,5 \mathrm{~mm}$ \\
\hline Panjang (meter) & 6,0348 & 0,000011 & 6,03 & 6,045 & $6 \pm 0,05 \mathrm{~m}$ \\
\hline Berat $(\mathbf{k g})$ & 45,776 & 0,0056 & 45,644 & 45,918 & $45 \pm 1 \mathrm{~kg}$ \\
\hline
\end{tabular}

Sumber: Data diolah, 2019

Rata-rata diameter pipa ERW tahap II $88,185 \mathrm{~mm}$ serta varians sebesar 0,0128 $\mathrm{mm}$ dengan nilai minimum sebesar $87,975 \mathrm{~mm}$ dan nilai maksimum hampir mendekati batas spesifikasi atas dengan nilai sebesar 88,46. Sedangkan untuk panjang pipa rata-rata panjang sebesar 6,0348 meter dengan varians yang cukup kecil dengan nilai 0,000011 meter, nilai minimum dari panjang pipa berada di atas nilai target sebesar 6,03 meter dan nilai maksimum hampir mendekati nilai batas spesifikasi atas sebesar 6,045 meter. Rata-rata untuk variabel berat menunjukkan nilai $45,776 \mathrm{~kg}$ artinya nilai rata-rata berat mempunyai selisih 0,776 dari nilai target. Berdasarkan nilai minimum dan maksimum berat pipa menunjukkan nilai yang lebih besar daripada nilai target yang ditetapkan sehingga terindikasi variabel berat memiliki akurasi yang rendah namun masih dalam batas spesifikasi yang telah ditetapkan.

\subsection{Monitoring Variablitas Proses pada Data Tahap II}

Untuk memonitor variabilitas proses pada tahap II maka seblumnya dilakukan pengujian apakah variabilitas proses pada data tahap I telah terkendali atau tidak. Karena data pada tahap I telah terkendali maka dilanjutkan dengan menghitung determinan dari HDS. Berdasarkan Persamaan (4.2), Matriks kovarian dari HDS sebagai berikut:

$$
S_{H D S}=\left[\begin{array}{clr}
1.392281 \mathrm{e}-02 & -1.745682 \mathrm{e}-05 & 0.0120874852 \\
-1.745682 \mathrm{e}-05 & 1.012936 \mathrm{e}-05 & -0.0002827772 \\
1.208749 \mathrm{e}-02 & -2.827772 \mathrm{e}-04 & 0.0535525013
\end{array}\right]
$$

determinan dari $S_{H D S}$ adalah $\left|S_{H D S}\right|=5.062202 \mathrm{e}-09$. 


\section{Suci Barlian Sari, Erna Tri Herdiani, Nasrah Sirajang}

Setelah dilakukan pengujian secara normal multivariat dan uji independensi pada tahap II maka selanjutnya di lakukan analisis untuk memantau apakah terjadi variabilitas proses ketika observasi baru tersedia. Pada tahap ini disebut juga sebagai Augmented Data Set (ADS). Pada tahap ADS ini akan dilakukan pengamatan sebanyak 40 individu sehingga nilai determinan dari ADS berjumlah 40. Berdasarkan persamaan (4.3) diperoleh nilai determinan ADS tiap individu, Setelah diperoleh determinan dari ADS maka nilai Wilks dapat dihitung berdasarkan Persamaan (4.4) dengan $\mathrm{n}=45, \mathrm{p}=3$ dan $\left|S_{H D S}\right|=$ 5.062202e-09, Untuk melihat apakah terdapat variabilitas proses pada tahap II, maka dilakukan plot antara nilai Wilks dan LCL, di mana LCL dapat dihitung berdasarkan persamaan (4.7) sehingga plot dari nilai Wilks dan LCL dapat dilihat pada Gambar 4.1 berikut:

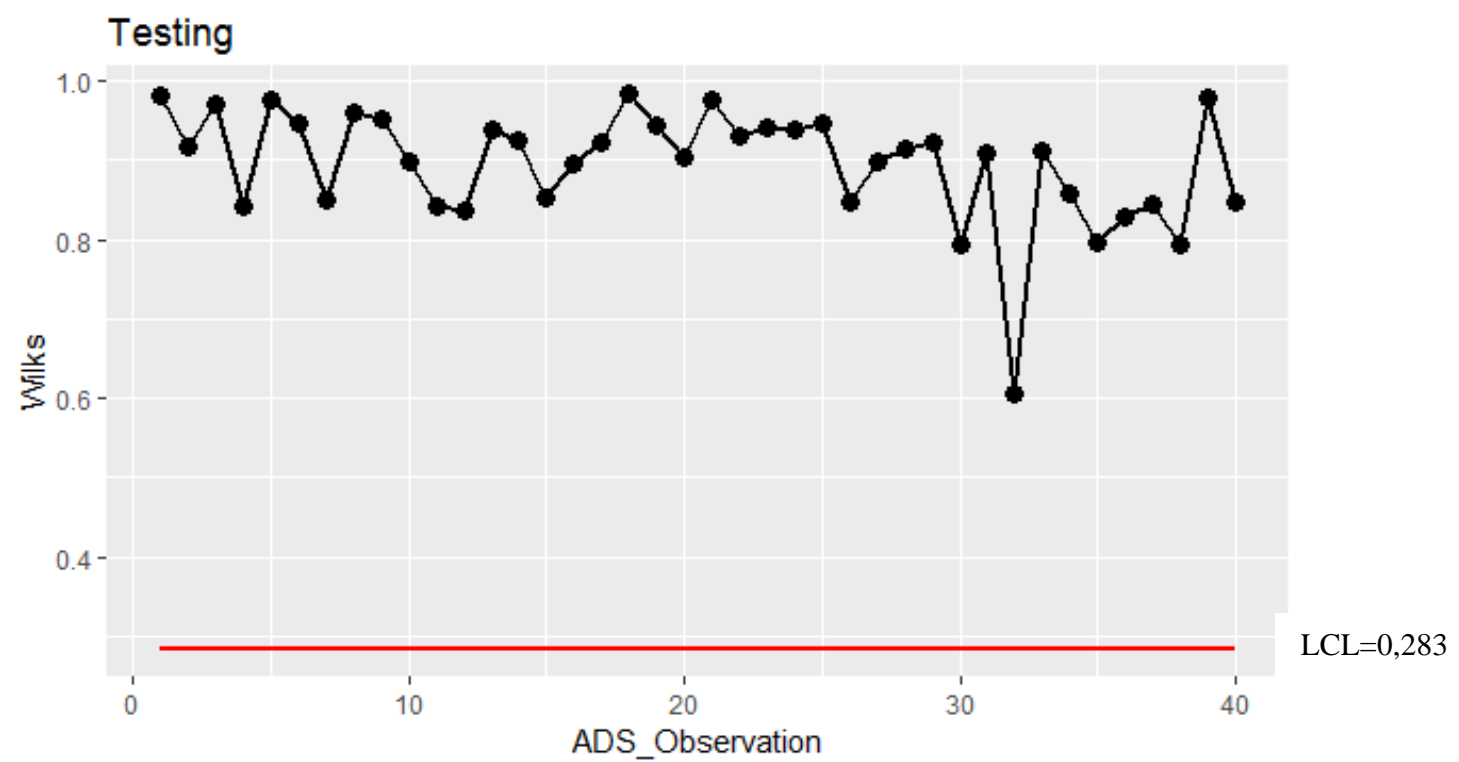

\section{Gambar 4.4 Bagan kendali Wilks dengan 40 observasi individu}

Berdasarkan gambar diatas, terlihat bahwa semua pengamatan berada dalam batas kendali. Pada gambar diatas terlihat ada satu observasi yaitu observasi ke-32 yang cenderung mendekati LCL dengan nilai Wilks sebesar 0,6 selebihnya semua observasi mendekati nilai 1 yang artinya peluang pipa ERW memenuhi batas spesifikasi yang ditetapkan oleh perusahaan industri dengan kualitas yang sangat baik.

\subsection{Indeks Kemampuan Proses}

Setelah diperoleh bagan kendali Wilks dalam keadaan pengamatan in control, maka langkah selanjutnya adalah menaksir kapabilitas proses $(C p)$. Berikut murupakan indeks kapabilitas proses secara multivariat pada proses produksi pipa ERW tahap II.

Tabel 4.3 Indeks Kapabilitas Proses Pipa ERW tahap II

\begin{tabular}{|c|l|}
\hline Indeks Kapabilitas Proses & Nilai \\
\hline Cpm & 2,53869 \\
\hline
\end{tabular}

Menggunakan program $\mathrm{R}$ diporoleh nilai indeks kapabilitas proses (Cpm) sebesar 2,5386 artinya kapabilitas proses dari produksi pipa ERW menggunakan bagan kendali statistik Wilks secara multivariat 


\section{Suci Barlian Sari, Erna Tri Herdiani, Nasrah Sirajang}

telah capable dan sangat baik serta sesuai dengan batas spesifikasi yang telah di tentukan oleh perusahaan.

\section{Kesimpulan dan Saran}

\subsection{Kesimpulan}

1. Untuk memonitoring variabilitas proses dapat dihitung dengan menggunakan persamaan berikut:

$$
W=\frac{\left|S S_{H D S}\right|}{\left|S S_{A D S}\right|}=\left(\frac{n-1}{n}\right)^{p} \frac{\left|S_{H D S}\right|}{\left|S_{A D S}\right|}
$$

Adapun Batas kendali untuk menentukan variablitas proses berdasarkan statistik Wilks yaitu:

$$
L C L=\operatorname{Beta}_{\left(\alpha \frac{n-p}{2}, \frac{p}{2}\right)}
$$

2. Semua pengamaan yang dilakukan secara individu berada dalam batas kendali, artinya produksi pipa ERW memenuhi batas spesifikasi yang ditetapkan oleh perusahaan industri dengan kualitas yang sangat baik.

3. Berdasarkan hasil analisis kapabilitas proses, nilai $C p$ untuk bagan kendali Wilks pada produksi pipa ERW di Pt. X yaitu sebesar 2,5386 artinya kapabilitas proses dari produksi pipa ERW menggunakan bagan kendali statistik Wilks secara multivariate telah capable dan sangat baik serta sesuai dengan batas spesifikasi yang telah di tentukan oleh perusahaan.

\subsection{Saran}

Adapun saran untuk penelitian selanjutnya adalah melakukan perbandingan dengan data yang sama yaitu data proses produksi pipa ERW di PT. X menggunakan metode Principal Component Analysis (PCA).

\section{DAFTAR PUSTAKA}

[1] Bothe, R. D. 1997. Measuring Process Capability. McGraw-Hill Companies, United States of America.

[2] Djauhari, M. A. 2011. Geometric Interpretation of Vector Variance. Universiti Teknologi Malaysia. Jurnal Matematika, Volume 27, Nomor 1, 51-57.

[3] Johnson, R. D. W. 2007. Applied Multivariat Statistical Analysis, 5th ed. New Jersey: Prentice Hall.

[4] Mason, R.L., Chou, Y.M., \& , J.C.Young. 2009. Monitoring variation in a multivariate process when the dimension is large relative to sample size, Commun. Statist. Theor. and Math. 38 pp. 939-951.

[5] Montgomery, D.C. 2009. Introduction to statistical quality control (6 ${ }^{\text {th }}$ ed.) Arizona State University:

[6] Noor, A.M \& Djauhari, M.A. 2010. Monitoring the variability of beltline moulding process using Wilks Statistics. Journal of Fundamental science, vol 6, no. 2, pp.116-120,2010

[7] Sahabuddin, dkk. 2013. Pengendalian Proses Variabilitas Multivariate Melalui Vektor Variansi. Tesis. Program Studi Matematika Fakultas Matematika dan Ilmu pengetahuan Alam. Makassar. Universitas Hasanuddin.

[8] Susanto, A.M. 2017. Statistical Quality Control on Process Electric Resistence Welded (ERW) Pipe in PT X. Skripsi. Program Studi Matematika Fakultas Matematika dan Ilmu pengetahuan Alam. Surabaya: Institute Teknologi Sepuluh November. 